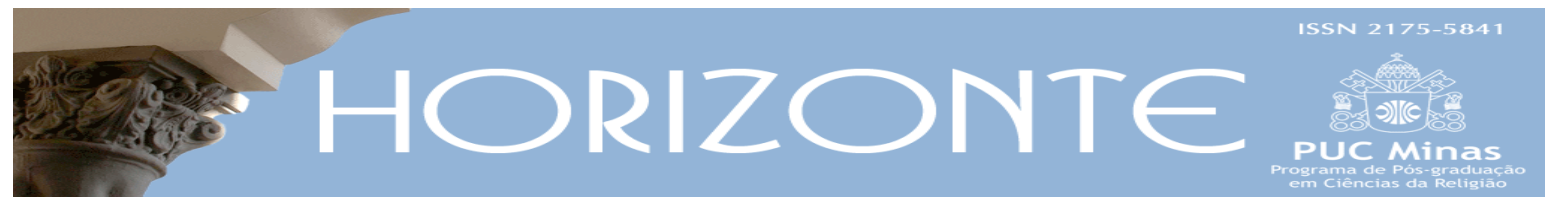

Temática Livre - Artigo original

DOI - 10.5752/P.2175-5841.2015v13n38p1080

\title{
A última morada dos defuntos: os locais de sepultura na Braga setecentista
}

\author{
The last dwelling of the dead: the places of burial in the Braga of the XVIII \\ century
}

\author{
Norberto Tiago Gonçalves Ferraz*
}

\begin{abstract}
Resumo
Este artigo pretende analisar e estudar os principais locais de sepultamento escolhidos pelos bracarenses no século XVIII. Ele insere-se numa investigação doutoral mais vasta sobre a temática da vivência da morte e a procura pela salvação da alma entre os habitantes de Braga ao longo desta centúria. O presente texto procede a uma análise tanto num plano generalista, como a um nível mais detalhado. Os dados obtidos apontam claramente no sentido de uma preferência por certas igrejas paroquiais e confraternais localizadas na cidade. Procuramos também demonstrar ao leitor que dentro das igrejas havia diferentes espaços de sepultamento, conforme o perfil social de cada um. Para além destes aspectos, o presente artigo procura igualmente apresentar as diferentes motivações que estariam na base das escolhas efectuadas pelos bracarenses. Este trabalho foi possível mediante 0 estudo de 250 testamentos locais, bem como dos dados dos arquivos de algumas confrarias citadinas.
\end{abstract}

Palavras-chave: Braga; sepultamentos; testamentos; igrejas.

\begin{abstract}
This article wants to analyse and study the major places of burial chosen by the inhabitants of Braga in the XVIII century. It comes from a more large doctoral investigation about the thematic of the experience of death and the search for the soul salvation among the inhabitants of Braga during this century. The present text makes an analysis not only in a general dimension but also in a more detailed level. The gathered data clearly point towards a major choice for the churches of the parishes and confraternities located in the city. We also seek to show to the reader that in the temples there were different places ob burial, in conformity to the social profile of each person. Beyond this points, the present article wants to show the various motivations on the basis of the choices made by the inhabitants of Braga. This work was possible by the study of 250 local testaments, and the data from the archives of some confraternities of the city.
\end{abstract}

Keywords:Braga; burials; testaments; churches.

Artigo recebido em 09 de abril de 2015 e aprovado em 30 de junho de 2015.

* Doutor em História Moderna. Membro do Lab2pt - Universidade do Minho. País de origem: Portugal. E-mail: Norberto_tiago@iol.pt.

Horizonte, Belo Horizonte, v. 13, n. 38, p. 1080-1102, abr.jun 2015 - ISSN 2175-5841 


\section{Introdução}

A última etapa no percurso dos restos mortais dos defuntos era a sua inumação no local de sepultura, onde aguardariam pela ressurreição até ao dia do juízo final. Os estudos realizados sobre esta temática têm vindo a demonstrar que, desde o início da Idade Moderna, no mundo ocidental católico, estava bastante disseminada a prática do enterro dos cadáveres nas igrejas das localidades. ${ }^{1}$ Todavia, tal não significava que não existissem também alguns cemitérios para receber os corpos dos defuntos, os quais estavam situados igualmente dentro das povoações, sem estarem convenientemente vedados. As populações utilizavam-nos frequentemente para atividades mundanas $^{2}$ e não era raro que os animais desenterrassem os restos mortais dos defuntos. 3 Deste modo, a última morada dos mortos estava inserida na vivência quotidiana dos vivos, fosse ela localizada exteriormente no cemitério, ou nas igrejas onde os vivos se reuniam regularmente para tomarem parte nas celebrações religiosas: eram dois mundos que se encontravam próximos e que se cruzavam. 4

A prática do enterro nas igrejas tinha sido iniciada ainda na Idade Média, 5 pois acreditava-se que o enterro em solo sagrado eclesial ajudava a garantir a salvação, beneficiando as almas com os sufrágios aí celebrados. Se inicialmente este foi um procedimento dos indivíduos pertencentes aos grupos privilegiados da sociedade medieval, enquanto as restantes pessoas eram enterradas nos cemitérios

\footnotetext{
${ }^{1}$ Se na Idade Média, o corpo era geralmente confiado à Igreja, pouco importando o lugar de sepultura, na Idade Moderna há uma crescente preocupação de identificar esse local dentro de uma igreja ou de um convento. Para este assunto consulte-se Ariés(1975, p. 58).

${ }^{2}$ Para este assunto confira-se igualmente Favre (1978, p. 25).

${ }^{3}$ A propósito da má vedação dos cemitérios leia-se também Soares (1993 p. 342).

${ }^{4}$ Sobre a importância para a salvação das almas que os homens da Idade Moderna atribuíam ao sepultamento dos corpos nas igrejas citamos os estatutos de 1702 da irmandade de Santa Cruz: "É na igreja católica muito antigo, pio e louvável costume enterrarem-se os corpos dos fiéis cristãos defuntos nas igrejas, porque como são lugares a que os mesmos fieis concorrem para ouvir e assistir às missas, e ofícios divinos, e orações, vendo as sepulturas se lembrem de encomendar a Deus nosso senhor as almas dos defuntos especialmente as dos seus, para que mais cedo sejam livres das penas do purgatório e tenham juntamento os mesmos fieis vivos memorias da morte, e se consolem esperando que o mesmo se faça por suas almas, quando desta vida partirem, segundo a lembrança que eles tiveram dos defuntos." Arquivo da Igreja de Santa Cruz doravante AISC, Fundo da irmandade de Santa Cruz, Livro de estatutos da irmandade de Santa Cruz, 1664, 1702, 1762, 1773, fl. 278.

${ }^{5}$ Veja-se relativamente a este facto Carvalho (2001-2002, p. 18).
} 
em volta das igrejas, ${ }^{6}$ na Idade Moderna esta prática tinha-se alargado a quase todos os grupos sociais, com exceção dos pobres.7

\section{Categorização geral dos principais locais de sepultamento}

A urbe bracarense, no século XVIII, era a cabeça de um importante arcebispado, com origens eclesiásticas ainda no período romano. Simultaneamente o arcebispo era, desde tempos anteriores à fundação da nacionalidade portuguesa, o senhor da cidade. O titular do cargo disputava, aliás, o título de "Primaz das Espanhas", com o metropolita de Toledo. O peso e influência da Igreja eram por isso notórios na formação das mentalidades e comportamentos sociais dos seus habitantes. A cidade tinha diversos templos e o culto, as festas e manifestações religiosas condicionavam o seu devir quotidiano. O tecido socio-económico populacional de então mostrava uma população que trabalhava sobretudo no sector secundário (em especial no têxtil) e no sector terciário do comércio, serviços e funcionalismo público da vida cívica, política e eclesiástica. ${ }^{8}$

Ora como se traduzia esta realidade, relativamente à questão dos sepultamentos bracarenses nesta centúria? O estudo que levamos a cabo demonstrou que em Braga a preferência pelo enterro nos templos religiosos estava igualmente difundida, embora saibamos da existência de um “cemitério,” junto ao hospital da Misericórdia, onde se enterravam alguns defuntos, principalmente os doentes pobres falecidos neste estabelecimento de assistência.9 Esta instituição tinha igualmente um outro cemitério próprio no claustro da Sé, onde enterrava os

\footnotetext{
${ }^{6}$ Os corpos dos cristãos já na Época Medieval deviam ser enterrados em terra cristã para aguardarem a ressurreição. Existiam, por isso, os cemitérios, geralmente em volta das igrejas, com esse fim expresso. Todavia, a inumação nestes locais tornava o defunto anónimo e, para escapar a este destino, os mais ricos começam a solicitar crescentemente à Igreja a possibilidade de sepultamento dentro dos templos, em túmulos privativos e identificados. Consulte-se a este respeito Lorcin (1993, p. 245, 248, 251). Mais tarde, a restante população solicitou a sua inumação dentro das igrejas, na zona da nave, ainda que geralmente sem qualquer identificação sobre a sua identidade.

${ }^{7}$ Sobre o papel pioneiro dos indivíduos de poder político e social, na procura de enterros no interior das igrejas confira-se o que dizem Binski (1996, p. 72, 80-84) e também Veloso (1988, p. 10).

${ }^{8}$ Consulte-se Gomes (2002, p. 50-51.) e também (Soares, p. 79).

${ }^{9}$ Em relação ao cemitério do hospital da Misericórdia e sua funcionalidade veja-se Castro (2001, p. 262). Na Época Moderna, a Misericórdia possuía ainda, efetivamente, um espaço no claustro de Santo Amaro, para aí poder sepultar os pobres e enjeitados. Essa zona tinha algumas oliveiras. Veja-se sobre este assunto Castro (2006, p. 596-598).
} 
mais desfavorecidos. Para levarmos a cabo um estudo aprofundado sobre os principais locais de sepultamento na Braga setecentista, analisamos 250 testamentos de bracarenses do século XVIII, equitativamente distribuídos num total de 50, por cada 20 anos. Os dados compulsados nesta amostragem demonstraram como estava bem difundida, entre os testadores bracarenses deste século, a procura do solo sagrado, para o repouso final dos seus corpos.

O estudo da nossa amostra de testamentos revelou, numa categorização mais genérica, que os bracarenses se dividiam entre as igrejas das suas paróquias ${ }^{10}$ e as igrejas pertencentes às confrarias da cidade, ${ }^{11}$ na hora de escolherem o local onde desejavam que os seus restos mortais pudessem descansar para a eternidade. Cerca de $80 \%$ dos testadores da nossa amostragem escolheram estes templos como última morada. Em termos comparativos, podemos verificar que era significativamente maior a percentagem de testadores que designavam as igrejas de confrarias como locais de sepultura. Cerca de $48 \%$ assim o fizeram, em comparação com os que escolhiam as igrejas das suas paróquias da cidade, os quais se ficaram por uma percentagem a rondar os 32\%.12 Parece ser evidente que a preferência de muitos fiéis inclinava-se no sentido de o seu corpo repousar eternamente na igreja de uma irmandade, em detrimento da igreja paroquial.13

\footnotetext{
${ }^{10}$ As freguesias da cidade de Braga no século XVIII eram as da Sé, São João de Souto, São Vítor, Maximinos, Cividade e São Lázaro.

${ }^{11}$ Nesta centúria as confrarias possuidoras de uma igreja própria na cidade eram a irmandade de São Vicente, a irmandade de Nossa Senhora-a-Branca, a irmandade de Santa Cruz, a irmandade do Bom Jesus dos Santos Passos e a irmandade da Misericórdia. A estas se deve acrescentar a igreja da Ordem Terceira de São Francisco de Braga.

${ }^{12}$ Arquivo Distrital de Braga, doravante ADB, Testamentos do Fundo de Provedoria, Cotas 17, 18, 20, 22, 26, 27, 28, 29, 31, 33, 37, 38, $39,42,45,46,47,49,50,52,54,55,56,57,59,60,61,63,64,67,68,69,72,73,74,78,80,82,83,85,86,88,89,91,93,94,95,98$, $100,101,102,104,111,112,113,114,116,117,118,119,121,125,128,131,137,143,148,150,151,152,153,154,155,157,161$, $162,163,164,165,169,170,171,172,173,175,176,177,179,188,193,196,199,201,202,206,209,212,214,218,221,225,227$, $233,234,253,255,256,257,262,264,269,271,282,283,287,288,292,293,298,301,303,305,308,310,315,316,319,326,327$, $328,329,335,347,350,371,386,387,392,395,399,404,408,409,410,412,417,421,422,423,425,426,427,428,430,432,434$, $435,442,443,444,448,454,455,458,462,467,468,470,472,495,501,519,524,540,549,551,552,569,583,593,604,608,637$, $1717,1718,1721,1723,1726,1727,1728,1731,1732,1733,1734,1801,2987,3012,3018,3432,3797,4293,4294,4297,4298,4301$, 4302, 4303, 4306, 4308, 4310, 7153, 7229, 8057, 8058, 8059, 8064, 8065, 8067, 8068, 8070, 8077, 8078; Arquivo da Igreja da Sé de Braga, doravante AISB, Livro de testamentos da freguesia da Sé, 1738-1785, fls. 10-10v., 12-13, 19-19v., 26v.-27v., 32-33, 35-36, 40v.41, 50v.-51, 67v.-68, 74-75, 85-85v., 89-89v., 111v.-112, 129-130., 134v.-135, 135, 147-148, 160-161, 165v.-166v., 175-176, 189, 197v.198; Livro de testamentos da freguesia da Sé, 1785-1814, fls. 5-5v., 37v.-38, 49v.-50, $57 \mathrm{v} .-58$

${ }^{13}$ Esta preferência por outros templos que não o da igreja paroquial sucedia, por exemplo, também em Cádiz no século XVI, onde a igreja da Misericórdia local e a do mosteiro de São Francisco eram os templos mais procurados para os sepultamentos. Leia-se sobre este ponto Montéros Sánchez (2005, p. 150-154).
} 
Que motivos levariam a esta decisão? Esta tendência estaria possivelmente relacionada com o facto de vários testadores pertencerem à confraria proprietária da igreja onde desejavam ser sepultados, mostrando, deste modo, sentirem maior apego à sua instituição confraternal, do que à comunidade paroquial. Uma outra vantagem para os irmãos das instituições confraternais que possuíam igrejas, residia no facto de poderem ser sepultados gratuitamente nestes templos, ainda que tivessem de pagar ao pároco da igreja paroquial o direito referente ao sepultamento. ${ }^{14}$ Em relação aos não confrades, não podemos deixar de colocar também a hipótese de os custos de sepultura, em algumas das igrejas confraternais, serem mais baixos, comparativamente com os praticados na igreja paroquial. ${ }^{15} \mathrm{E}$, em outros casos de igrejas de confrarias, como as de Santa Cruz ou da Misericórdia, seriam porventura motivos de prestígio social os que motivariam estes testadores a escolher os seus templos como últimas moradas. ${ }^{16}$

A análise testamental permite igualmente estabelecer outras ilações. Apesar de existirem alguns testadores que procuravam os templos das ordens religiosas para serem aí sepultados, a sua percentagem era minoritária, cifrando-se num total de $10 \%$. Sabemos que no século XVIII em Braga existiam sete conventos masculinos: o dos Religiosos Menores de São Francisco, o dos Religiosos da Companhia de Jesus, o convento de Montariol, o convento dos Religiosos Eremitas Calçados de Santo Agostinho no Pópulo, o dos Religiosos Carmelitas Descalços, o Colégio do Seminário e a Congregação do Oratório de São Filipe Neri. Paralelamente existiam os conventos femininos de Nossa Senhora dos Remédios,

\footnotetext{
${ }^{14}$ Os direitos paroquiais de sepultura eram todos os estipêndios que os familiares tinham de pagar às paróquias onde eram enterrados. Sobre os direitos paroquiais nos enterros e funerais veja-se García Fernández (1994, p. 102). Além disso, aparentemente, os paroquianos tinham de pagar também ao seu clérigo para que este fizesse a "oração annua". Arquivo Distrital de Braga doravante ADB, Testamentos do fundo de Provedoria, Cotas 398, 442, 454, 455.

${ }^{15}$ Desconhecemos o preço dos sepultamentos nas igrejas paroquiais. Sabemos que na igreja de São Vicente, para os não confrades, abaixo das grades, variaram entre 200 réis durante a maior parte da centúria, até 700 no final do século. A estes a irmandade acrescentou mais 200 réis para pagamento ao seu coveiro. Arquivo da Igreja de São Vicente, doravante AISVTE, Fundo da irmandade de São Vicente, Livro de termos de mesa da irmandade de São Vicente, 1701-1720, fls. 125-125v.; Livro de termos de mesa da irmandade de São Vicente, 1781-1790, fls. 80-80v.; Livro de estatutos da irmandade de São Vicente, 1768, fls. 55, 61. Na igreja de Nossa Senhora-a-Branca, o preço total pelos sepultamentos variou entre 200 e 300 réis, acrescidos de mais 200 e 100 réis respectivamente, para pagamento ao seu coveiro. Arquivo da Igreja de Nossa-Senhora-a-Branca, doravante AINSB, Fundo da irmandade de Nossa Senhora-a-Branca, Estatutos da confraria de Nossa Senhora das Neves, sita na capela da Senhora-a-Branca, 1723, fl. 21; Estatutos da irmandade de Nossa Senhora das Neves sita na capela da Senhora-a-Branca, 1768/1773, fls. 37-39.

${ }^{16}$ Depois da sua construção, no século XVI, as sepulturas na igreja da Misericórdia conheceram uma crescente procura como refere Castro (2006, p. 593-594).
} 
de Nossa Senhora da Conceição, Nossa Senhora da Penha de França, convento do Salvador, convento de Santa Teresa do Carmo e o convento de Santa Isabel. Este número considerável e diversificado de ordens religiosas presentes na cidade poderiam à partida antecipar um maior impacto dos seus templos nas escolhas sepulcrais dos bracarenses, mas, na verdade só alguns destes templos foram indicados pelos testadores analisados, como veremos mais à frente. ${ }^{17}$

As evidências apontam no sentido de os conventos bracarenses não serem locais que cativassem o interesse dos testadores por nós estudados, na hora de decidirem a sua última morada. É possível que os bracarenses não sentissem uma ligação profunda às igrejas das ordens religiosas. As pessoas sentiriam maior proximidade com a igreja da sua paróquia ou da sua confraria, escolhendo-as preferencialmente como a sua última morada. ${ }^{18}$

Um outro aspeto relevante a reter desta análise prende-se com o facto de terem sido poucos, entre os estudados, os testadores que deixaram ao arbítrio de outros, o local de sepultura. Parece ser claro que os bracarenses consideravam a designação da sua última morada como algo de muito importante, que não queriam deixar ao critério de outrem. ${ }^{19}$ Após a morte, a alma podia ter partido, mas os vivos consideravam ser fulcral que o corpo tivesse um lugar de repouso digno, segundo a sua vontade.

\section{Análise individualizada dos locais de sepultamento}

Se nos debruçarmos sobre uma análise mais detalhada e individual relativamente aos templos especificamente escolhidos pelos testadores como última morada, estes demonstraram que, apesar da grande dispersão de escolha

\footnotetext{
${ }^{17}$ Leia-se Silva, (2011, p. 30).

${ }^{18} \mathrm{Em}$ Ferrol, Espanha, no século XVIII, os seus habitantes preferiam igualmente o enterro na igreja paroquial em detrimento da que pertencia ao convento franciscano local. Para este aspeto leia-se Martín García (2004, p. 443).

${ }^{19}$ Em contrapartida, em Paris, desde 1730, eram cada vez mais os que deixam a escolha da sepultura a arbítrio dos herdeiros e testamenteiros. Sobre este facto consulte-se Chaunu (1978, p. 441-442).
} 
das igrejas, existia uma certa preferência por alguns locais: a Sé Primaz de Braga, especialmente o seu claustro de Santo Amaro, para além das igrejas das irmandades de São Vicente, de Santa Cruz e de Nossa Senhora-a-Branca. Em conjunto, estes quatro templos congregaram $58 \%$ das escolhas efetuadas. De forma mais detalhada, a Sé recolheu perto de $21 \%$ de testadores, enquanto a igreja de São Vicente teve a preferência de $14 \%$, percentagem igual à de Santa Cruz, enquanto a igreja de Nossa Senhora-a-Branca teve somente 9\%. Com pequenas percentagens, entre o total de testamentos analisados, mas ainda assim registando números que devemos assinalar, estiveram os que elegeram as igrejas paroquiais de São João de Souto, de São Vítor e de Maximinos. Dentro dos mesmos valores percentuais, encontramos os testadores que escolheram a igreja da Santa Casa da Misericórdia de Braga e a da Ordem Terceira de São Francisco. ${ }^{20}$ As igrejas dos conventos, como referimos, tiveram uma procura reduzida, entre os testadores analisados. Entre as igrejas conventuais a do convento do Carmo foi a mais procurada, com cerca de 4,5\% do total de testadores analisados, sendo também indicadas a dos Eremitas de Santo Agostinho, a das religiosas da Conceição, a das religiosas Remédios e a das religiosas do Salvador.

Focando a nossa análise primeiramente na relevância das igrejas paroquiais da Sé, de São João de Souto e São Vítor, esta ficava a dever-se ao facto de estas freguesias serem as mais populosas da cidade, sendo, por isso, expetável que tivessem esta relevância entre os testadores. ${ }^{21}$ Contudo, em relação à Sé, pensamos que este local merece uma reflexão mais atenta. Na verdade, a maioria dos testadores que escolheu a Sé, referiu-se aos seus claustros, em especial o de Santo Amaro, como local de sepultamento. Ora esta zona claustral tinha, no seu interior, uma área utilizada pelos pobres da freguesia como local de enterro, para além de outras áreas adstritas a altares de vários santos. Assim sendo, para os fiéis,

\footnotetext{
${ }^{20}$ As freguesias da Sé, de São João do Souto e de São Vítor eram aquelas em que se concentrava o grosso da população citadina bracarense, sendo este igualmente um fator a ter em atenção. Refira-se igualmente que as igrejas confraternais de Santa Cruz, São Vicente, Nossa Senhora-a-Branca, Misericórdia ou a da Ordem Terceira situavam-se nestas freguesias.

${ }^{21}$ Embora existissem confrarias instaladas nestas igrejas paroquiais, essas instituições não eram proprietárias das mesmas, não tendo sequer nesses templos áreas de sepultamento reservadas aos seus irmãos. Estes não tinham qualquer tratamento preferencial em relação aos restantes indivíduos, no que dizia respeito a esta questão.
} 
sobretudo da freguesia da Sé, o claustro poderia ser uma zona de sepultamento acessível às suas possibilidades, com a vantagem de estar integrada no templo sagrado mais importante e central da cidade. Existiria certamente a crença de que as almas dos defuntos aí sepultados poderiam beneficiar espiritualmente da proximidade a um edifício onde se celebravam diariamente um número assinalável de missas e outros atos pios. Para além disso, era à igreja da Sé bracarense que o arcebispo se deslocava para as celebrações religiosas e diversos prelados foram aí sepultados. A importância deste templo e o facto de a principal autoridade religiosa e política bracarense de então, ${ }^{22}$ a escolher prioritariamente como local de sepultura, certamente influenciavam muitos fiéis na hora de escolherem a sua última morada.

Já no que diz respeito às igrejas confraternais, sublinhamos a importância dos templos das confrarias de São Vicente, de Nossa Senhora-a-Branca e de Santa Cruz. O estudo de fontes documentais em arquivo relativas às duas primeiras confrarias demonstrou o preço relativamente moderado praticado por estas instituições nos enterros dos não confrades nas suas igrejas. Para além disso, os enterros dos irmãos dentro das igrejas destas instituições eram tendencialmente gratuitos, ao passo que no interior das igrejas paroquiais tal não acontecia, o que certamente levava muitos indivíduos membros das irmandades a escolher estas igrejas em particular.

Este deve ser certamente um fator explicativo. Por outro lado, eram duas confrarias de grande importância na cidade, com um elevado número de irmãos, provenientes dos diversos grupos sociais. Na verdade, a irmandade de São Vicente era descrita como sendo a do "povo da cidade," o que nos mostra o grau de difusão desta instituição na zona urbana. Deste modo, parece-nos compreensível que muitos dos seus habitantes solicitassem ser aí sepultados, permanecendo na morte

\footnotetext{
${ }^{22}$ Recordemos que, desde a Idade Média até perto do fim do século XVIII, o arcebispo de Braga era o titular de um importante senhorio, o couto bracarense. Veja-se Oliveira (2011, pp. 18-21).
} 
fiéis a uma confraria de composição social abrangente, com a qual se identificavam. A estas razões podemos ainda juntar o facto de os confrades e os benfeitores das confrarias de São Vicente e de Nossa Senhora-a-Branca, bem como a restante população, poderem beneficiar de muitas indulgências, nas missas celebradas nas igrejas destas organizações confraternais. ${ }^{23}$ A irmandade de São Vicente era especialmente rica em indulgências que procuravam aliviar as penas do Purgatório, concedidas nas missas celebradas por alma de qualquer pessoa. Por isso, é natural que muitos concluíssem pelo benefício no sepultamento em igrejas onde eram celebrados tantos sufrágios.

Por seu turno, a igreja de Santa Cruz deve ter sido escolhida por testadores mais abastados, ou que fizessem parte desta importante irmandade, ${ }^{24}$ constituída pela elite social da cidade, que procuravam a sua última morada na igreja de uma das confrarias mais prestigiadas e poderosas socialmente. ${ }^{25}$ Aliás, o seu número era superior, entre os testadores analisados, aos que pediram sepultura na igreja da Misericórdia da cidade, demonstrando o grau de influência social que a irmandade de Santa Cruz adquirira, no século XVIII, em comparação com outra irmandade de relevo como era a da Santa Casa. Simultaneamente, estes números poderão também ser sinais de uma certa decadência da preponderância da Santa Casa da Misericórdia de Braga, fundada no século XVI, entre as elites bracarenses ao longo do século XVIII. 26

Por seu turno, a escolha por parte de alguns testadores da nossa amostra, da igreja da Ordem Terceira de São Francisco, fundada em Braga no século XVII, ${ }^{27}$

\footnotetext{
${ }^{23}$ Arquivo da Igreja de Nossa Senhora-a-Branca doravante AINSB, Fundo da irmandade de Nossa Senhora-a-Branca, Estatutos da irmandade de Nossa Senhora das Neves, 1768/1773, fl. 31; Livro de termos de mesa da irmandade de Nossa Senhora-a-Branca, 17771787, fl. 84v.; Arquivo da Igreja de São Vicente doravante AISVTE, Fundo da confraria das Almas de São Vicente, Estatutos da irmandade das Almas de São Vicente, 1667, fls. 1-2; Fundo da irmandade de São Vicente, Livro de termos de mesa da irmandade de São Vicente, 1700-1720, fl. 231.

${ }^{24}$ Analisando muitos dos testadores que escolheram a igreja desta confraria como sepultura, constatamos que eram indivíduos com considerável poder financeiro, com bens de raiz ou pertencentes à irmandade.

${ }^{25} \mathrm{Na}$ Europa barroca os privilegiados chegavam a mandar construir imponentes túmulos ou sarcófagos de pedra no interior das igrejas.

${ }^{26}$ As Misericórdias perdem acompanhamentos e enterros, ao longo do século XVIII, fruto também da concorrência efetuada por outras confrarias e instituições como as Ordens Terceiras. Ou seja, a situação de decadência vivida pela Santa Casa de Braga era comum a muitas outras instituições congéneres como nos diz Sá (2000, p. 202).

${ }^{27} \mathrm{Na}$ cidade de Braga esta Ordem de irmãos terceiros foi fundada no ano de 1672. As ordens terceiras tinham origem no século XIII e eram associações de leigos e eclesiásticos, imbuídos pelo espírito franciscano. Leia-se Moraes $(2009$, p. 32, 63).
} 
parece refletir a consolidação desta ordem de leigos, na cidade, ainda que não chegasse a disputar a primazia das igrejas das confrarias de São Vicente, Santa Cruz e Nossa Senhora-a-Branca, nas preferências dos locais de sepultura. Os preços mais elevados para os sepultamentos dos indivíduos externos, que a Ordem Terceira praticava, em comparação com os das confrarias de São Vicente e de Nossa Senhora-a-Branca, poderão explicar o facto de esta instituição não as ter desalojado das suas posições, entre os testadores da amostra analisada. Por seu turno, a irmandade de Santa Cruz praticava preços superiores pelas sepulturas concedidas aos não confrades, na sua igreja, se os compararmos com aqueles efetuados na igreja da Ordem Terceira. Pensamos que a vitalidade, prestígio e influência daquela irmandade entre as elites sociais bracarenses permitiu manterlhe a sua posição, sem qualquer perda para a Ordem Terceira.

Com exceção dos que mencionaram especificamente o claustro da Sé de Braga, a maioria dos restantes testadores estudados apenas se referiu à igreja onde desejava ser sepultado, sem especificar a zona da sepultura. Na verdade, nos edifícios religiosos as inumações podiam acontecer em diferentes locais, conforme as possibilidades financeiras de cada um e a sua posição social. Cada zona correspondia também a um nível diferente de sacralidade, havendo, deste modo, áreas mais prestigiantes e sagradas de tumulamento, no perímetro de cada igreja. Assim, o espaço da capela-mor era, a nível religioso, o mais importante nas igrejas, pois nele eram celebradas as missas principais. ${ }^{28}$ Por isso, somente um número muito restrito de personalidades, individualidades importantes das elites e grupos do topo da pirâmide social, podiam aspirar ser aí enterradas. Era necessária uma licença eclesiástica que autorizasse a sepultura na capela-mor das igrejas, dado o cariz sacro dessa área, onde, por princípio, segundo as constituições sinodais bracarenses, só se sepultavam os padroeiros ou fundadores do edifício, os

\footnotetext{
${ }^{28}$ Sobre a importância religiosa e social da capela-mor enquanto espaço de enterramento veja-se Araújo (1997, p. 363-365) e também Gregório (1999, p. 42).
} 
comendadores, os abades e reitores, ${ }^{29}$ ou algum particular benfeitor que tivesse claramente direito sobre a dita capela.

Fora da capela-mor qualquer um estava habilitado a eleger livremente o seu lugar de sepultamento nas igrejas, mediante o pagamento correspondente. Não indicando essa localização, seria enterrado na sepultura de seus antepassados, se esta existisse. Se nenhuma destas situações se verificasse, o indivíduo seria sempre enterrado na igreja paroquial, de acordo com as possibilidades e decisões dos herdeiros. As campas na área fora da capela-mor deviam ser todas rasas. 30

A seguir à capela-mor, existia geralmente uma outra área nas igrejas, designada de transepto ou, de forma mais restrita, o cruzeiro. ${ }^{31}$ Por vezes, estava separada do restante espaço do interior do edifício, através de grades. ${ }^{2}$ Esta área intermédia podia ser utilizada como zona de sepultura, em princípio por qualquer pessoa, mas certamente que, ainda assim, continuava a ser um grupo relativamente pequeno o que podia pagar para ser sepultado nesse local, devido aos maiores custos que acarretava. 33 A maioria das pessoas era enterrada na zona interior da igreja abaixo das grades, designada como a nave, enquanto os mais pobres o eram no adro exterior do edifício, a título gratuito. 34

Em relação aos testadores analisados que não definiram o local específico de enterro nas igrejas, 35 presumimos que seriam provavelmente sepultados na zona abaixo das grades, por ser a área onde o povo em geral era sepultado, ou, seguindo as indicações clericais, nas sepulturas dos antepassados. Contudo, para além dos

\footnotetext{
${ }^{29} \mathrm{~A}$ respeito da reserva da capela-mor como local de sepultamento para estes indivíduos leia-se igualmente Raimundo (2007, p. 240241).

${ }^{30}$ Como explicitamente o referem as Constituições Synodais do Arcebispado de Braga (1697 p. 292, 294-295). As campas rasas estavam ao mesmo nível do chão. Estavam por isso excluídos monumentos funerários ou túmulos elevados que perturbassem esta norma.

${ }^{31} \mathrm{O}$ cruzeiro das igrejas desfrutava de maiores benefícios espirituais e conferia maior prestígio a quem era aí sepultado. Sobre este facto leia-se Araújo (2007, p. 392-393). Na verdade as sepulturas mais distintas encontravam-se efetivamente na capela-mor, no cruzeiro e junto aos altares colaterais. A este respeito leia-se Campos (2000, p. 50).

${ }^{32}$ Nas igrejas, no século XVIII, os devotos não podiam ocupar a zona da capela-mor como refere Faria (2006, p. 792).

${ }^{33}$ No início da Idade Moderna esta zona estava somente acessível às pessoas mais ricas e influentes.

${ }^{34}$ A respeito do sepultamento dos pobres no espaço exterior das igrejas, ou adro, confira-se Araújo (2007, p. 392).

${ }^{35}$ De igual modo, também em Zalamea la Real a maioria dos testadores não referia o local específico de sepultamento dentro das igrejas. Para este aspeto consulte-se García García (2004, p. 158).
} 
que designaram o claustro de Santo Amaro da Sé, um número reduzido de testadores indicou de modo mais específico, a localização da sua última morada, nas igrejas que escolheram. Na igreja de Nossa Senhora-a- Branca, Bento Francisco, um proprietário de casas e terras, e Andreia Gomes, viúva de um mercador, definiram, em 1706 e 1751 respetivamente, o seu sepultamento acima das grades interiores da igreja, ao passo que André do Vale, um indivíduo que parecia ter alguns meios financeiros, da rua do Carmo, determinou, em 1747, a inumação do seu cadáver abaixo das mesmas. 36

Por seu turno, o espadeiro António Rodrigues, em 1728, Andreia Vieira, mulher de Custódio Dias Peixoto (um espingardeiro dotado de grande riqueza), em 1737 e Mariana Ferreira, mulher do estalajadeiro António da Rocha, em 1709, quiseram ser enterrados acima das grades interiores da igreja da irmandade de São Vicente.37 Esta última testadora acrescentou querer o repouso dos seus restos mortais numa sepultura do lado "de Santo António," ou seja, na área adjacente ao altar desde santo. No fim do século XVIII, António José Ferreira Gomes, um "vendeiro" da ponte de Guimarães, definiu o seu enterro acima das grades na igreja de São Lázaro, enquanto Ângela Maria Ribeiro, mulher do cutileiro Jerónimo Pereira, quis ser sepultada abaixo das mesmas, na igreja do convento do Carmo. 38

Constatamos, deste modo delinear-se uma certa tendência sepulcral entre os bracarenses que exerciam ofícios mecânicos ou eram detentores de bens, e igualmente entre os seus parentes, a qual se refletia na procura do sepultamento acima da zona das grades. Não deixavam, todavia de existir exceções, como no caso do referido André do Vale ou da mulher do cutileiro Jerónimo Pereira. Teriam sepulturas de antepassados na zona abaixo das grades, manifestando deste modo vontade de manter este elo familiar? Não o sabemos.

\footnotetext{
${ }^{36} \mathrm{ADB}$, Testamentos do fundo de Provedoria, Cotas 233, 293, 1718.

${ }^{37}$ ADB, Testamentos do fundo de Provedoria, Cotas 78, 131, 8058.

${ }^{38}$ ADB, Testamentos do fundo de Provedoria, Cotas 495, 604.
} 
O padre Bento Ferreira Ribeiro, da rua dos Sapateiros, em 1717 e Antónia Teresa, do campo de São Sebastião, em 1796, definiram a capela de São Geraldo na Sé como última morada, ao passo que o chantre Afonso de Magalhães determinou, em 1741, a capela de São Pedro de Rates da Sé Primaz para o mesmo efeito, por aí estar sepultado seu tio. Como vemos parece haver uma certa tendência, entre alguns clérigos, pela escolha de certos locais específicos de sepultamento nas igrejas, especialmente em certas capelas internas de maior importância. De facto, os espaços de tumulamento na Sé de Braga eram variados, não se restringindo ao corpo principal da igreja ou ao seu claustro. Na verdade esta procura pelas capelas sepulcrais era extensível a membros da fidalguia como a testadora D. ${ }^{\text {a }}$ Antónia Maria de Sousa Montenegro, da casa dos Biscainhos, que foi sepultada na capela lateral de Santa Apolónia, na igreja do convento do Pópulo.39 Do mesmo modo, António de Almada Carvalho, cavaleiro professo da Ordem de Cristo definiu, em 1724, a zona da capela-mor como última morada. Este testador determinou a inumação do seu corpo na sepultura dos "padroeiros,"4o localizada na capela-mor do convento de Nossa Senhora da Conceição. Possivelmente seria familiar de alguém que no passado contribuíra para a fundação e crescimento desse convento, tendo, por isso, direito a uma sepultura privada em área tão distinta, restrita e privilegiada.

O que podemos constatar é que estes indivíduos possuíam capacidade e prestígios sociais, económicos e financeiros e pretendiam o descanso eterno numa zona capelar, separada das restantes áreas de sepultamento da igreja, configurando maior individualidade e prestígio à sua sepultura, da qual provavelmente deviam ser proprietários. ${ }^{41}$ Estas ilações claramente reforçam a ligação de certos grupos sociais a zonas de sepultamento específicas dentro das igrejas.

\footnotetext{
${ }^{39}$ ADB, Testamentos do fundo de Provedoria, Cotas 98, 435, 552, 1727.

${ }^{40}$ ADB, Testamentos do fundo de Provedoria, Cota 91.

${ }^{41}$ Para este assunto leia-se Martínez Gil (1993, p. 439).
} 
A viúva Ângela Ferreira, em 1706, indicou o seu tumulamento abaixo das grades divisórias, ou seja, na nave da igreja de São Vicente.42 Já o moleiro Francisco Rodrigues no ano de 1710 e a viúva Ana Fernandes em 1771, manifestaram o desejo expresso de serem enterrados no adro da igreja de São Vítor. Foram aliás, os dois únicos casos dentro da nossa amostra a enunciar explicitamente esta escolha pelo adro das igrejas. A sua frágil condição social deve ter sido a razão condicionadora desta opção.43 O estado de viuvez propiciava situações de carência social às mulheres da época moderna e o trabalho braçal de moleiro, num moinho propriedade de outrem, encontrava-se entre aqueles ofícios na base da pirâmide social de então. Era pois natural que nestes casos os indivíduos tivessem que se resignar com a sepultura nas referidas zonas.

Contudo, o adro parecia ser uma área que os testadores analisados procuravam evitar mencionar.44 É possível que outros indivíduos tivessem também em mente a possibilidade do local de sepultura poder vir a ser o adro da igreja, face à sua situação de pobreza, mas não o referissem especificamente no seu testamento, na esperança de que os herdeiros lhes proporcionassem um enterro debaixo do teto sagrado. Todavia, um outro motivo explicativo de um tão exíguo número de testadores terem mencionado o adro como local de sepultura, é o de uma parte significativa dos indivíduos mais pobres não fazerem testamento e, por isso, escaparem à nossa análise.

Algumas pessoas determinaram a sua última morada perto de certos altares. Em 1725, António Gonçalves Vieira, deixou prescrito o desejo de ser sepultado na sua igreja paroquial de Maximinos, junto ao altar de São Bento.45 Podia tratar-se de um devoto desta invocação. No fim do século XVIII, António Francisco Heitor, da rua dos Sapateiros, referiu querer ser enterrado na igreja do convento do

\footnotetext{
${ }^{42}$ ADB, Testamentos do fundo de Provedoria, Cotas 20, 78, 131, 8058.

${ }^{43} \mathrm{ADB}$, Testamentos do fundo de Provedoria, Cotas 153, 4301.

${ }^{44} \mathrm{Em}$ Coimbra, no século XVIII, era clara a preferência do interior das igrejas como locais de sepultamento em detrimento da zona exterior do adro. Consulte-se Roque (1982, p. 77-78).

${ }^{45} \mathrm{ADB}$, Testamentos do fundo de Provedoria, Cota 68.
} 
Pópulo, acima da zona dos púlpitos, ${ }^{46}$ no que podemos concluir uma aspiração pelo tumulamento numa área mais importante do interior do edifício. $47 \mathrm{~A}$ sua sepultura estava já contratada com os religiosos do mesmo convento. Por seu turno, os claustros da Sé foram bastante procurados como última morada, como já referimos. Se a maioria apenas mencionava o claustro de Santo Amaro em geral, alguns testadores indicaram uma localização mais específica para repouso dos seus restos mortais. Antónia da Costa em 1732 e Maria da Conceição em 1778 determinaram a sua inumação junto ao altar de Nossa Senhora do Desterro, enquanto em 1742, o mestre de capela da Sé, reverendo António Baião Magro, determinou a sua sepultura em frente ao altar de Nossa Senhora da Boa Memória.

Já Aleixo da Silva ${ }^{48}$ pediu para ser enterrado defronte ao altar de Santo António, no mesmo claustro, na sepultura onde se encontravam depositados os restos mortais de seu tio. 49 Francisco Alves, da rua dos Biscainhos, em 1718, referiu querer ser inumado nas "oliveiras dos claustros da Sé onde se sepultavam os pobres." 50 Este local devia tratar-se do cemitério particular da Misericórdia, no claustro da Sé de Braga, pois sabemos que esta instituição tinha á, junto às referidas oliveiras, uma zona reservada para a sepultura dos mais desfavorecidos da cidade, como anteriormente afirmámos. Com este gesto, pretendeu demonstrar o seu despojamento e a humildade cristãs no momento da morte. ${ }^{51}$

Em relação à escolha da sepultura nas proximidades dos referidos altares pensamos que, a exemplo do sucedido com o testador que desejou ser sepultado perto do altar de São Bento em Maximinos, a devoção aos santos como intercessores junto de Deus, para a salvação da alma, terá sido também uma razão

\footnotetext{
${ }^{46}$ ADB, Testamentos do fundo de Provedoria, Cota 549.

${ }^{47}$ Os púlpitos ficavam situados numa zona intermédia dos templos, geralmente incrustados na parede. Era daí que os pregadores se dirigiam aos fiéis. Veja-se Móran (1995, p. 137) e aindaNeves (1998, p. 258).

${ }^{48}$ ADB, Testamentos do fundo de Provedoria, Cotas, 74, 102, 196; Arquivo da Igreja da Sé de Braga doravante AISB, Livro de testamentos da Sé, 1738-1785, fls. 165v.-166.

${ }^{49} \mathrm{O}$ claustro barroco tinha, por vezes, altares e capelas dedicados a vários santos. Eram lugares propícios à meditação, oração e procura da perfeição espiritual por parte de frades e sacerdotes. Para este assunto confira-se Santiago (1991, p. 406).

${ }^{50}$ ADB, Testamentos do fundo de Provedoria, Cota 4308.

${ }^{51}$ Este homem era solicitador. No século XVIII o solicitador ou procurador intervinha em questões do funcionalismo judicial de âmbito diversificado.
} 
importante. Para além disso, nos altares eram celebradas missas que podiam constituir um benefício espiritual, para quem ali estivesse sepultado. $5^{2}$

Por seu turno, cinco indivíduos decidiram ser enterrados em áreas exclusivamente reservadas aos membros das suas confrarias.53 Para além destes testadores, o padre Manuel de Almeida, da rua de São Marcos e Manuel Gomes, da rua da Cruz da Pedra,54 determinaram o eterno descanso do seu corpo, junto à pia de água benta das igrejas onde foram sepultados. O primeiro, em 1708, foi sepultado próximo da pia de água benta do claustro da Sé e o segundo, em 1704, junto à pia da igreja de Santa Cruz, localizada do lado contíguo à rua do Anjo.55 Nenhum referiu as suas razões, todavia, talvez não andemos longe da verdade se considerarmos que a proximidade da sua sepultura à água sagrada e purificadora poderia ser um aspeto positivo para a salvação da alma. Ao considerarem a componente mística, salvadora e purificadora conferida à água benta, os testadores possivelmente esperavam que a sua sepultura fosse mais facilmente aspergida, propositada ou acidentalmente, pelos fiéis que tomavam este líquido para se benzerem. Seria, deste modo, mais um expediente salvífico, para algumas consciências pias. 56

Assim, ainda que a grande maioria dos testadores analisados (75\%) apenas referisse a igreja de repouso do seu corpo até ao juízo final, uma importante percentagem de $25 \%$, não deixou de assinalar de forma mais específica esta localização, indicando as áreas condizentes com o seu estatuto social, inserção

\footnotetext{
${ }^{52} \mathrm{Na}$ verdade, a escolha da sepultura podia estar motivada pela proximidade ao altar de um santo da devoção do defunto, que pudesse ser simultaneamente seu intermediário junto de Deus. Para este assunto confira-se Garcia Fernández (1996, p. 225).

${ }^{53}$ O padre Bento Correia, da rua das Águas, em 1727 e a testadora Benta Gomes, da rua da Cónega, em 1729, quiseram ser sepultados nos carneiros da igreja do convento do Pópulo, propriedade da irmandade dos Santos Passos. Por seu turno, Madalena Francisca, mulher do violeiro António Costa, da rua do Anjo, em 1706, o padre Frutuoso de Freitas e Almada, em 1716 e Ana de Lima, da rua do Souto, em 1725, determinaram o seu sepultamento nos "carneiros" da igreja de Santa Cruz por serem irmãos desta confraria e terem aí direito ao enterro gratuito. ADB, Testamentos do fundo de Provedoria, Cotas 63, 1733, 1734, 4310, 8068. No Brasil, desde meados do século XVIII, algumas irmandades introduziram nas suas igrejas "carneiros" para depósito dos mortos. Os "carneiros" destas igrejas eram, geralmente, cavidades longitudinais que formavam paredes localizadas nos subsolos das igrejas. Confira-se Reis (2004,p. 176186).

${ }^{54}$ ADB, Testamentos do fundo de Provedoria, Cotas 8064, 8078.

${ }^{55}$ Sobre os pedidos de sepultamento junto a certos altares e às pias de água benta leia-se igualmente Rubio Semper (1994, p. 244).

${ }^{56}$ Esta possibilidade foi também levantada por Reder Gadow (1986,p. 97). Por seu turno Pina (1996, p. 130) levanta a hipótese de uma relação com o simbolismo de um renascimento pela água do baptismo.
} 
confraternal, possibilidades financeiras e aspirações espirituais. Nesta percentagem, o claustro de Santo Amaro na Sé teve a maior relevância, como área de sepultamento dos defuntos, com $13 \%$ do total de testadores analisados. Por seu turno, os membros da fidalguia pareciam ter a suas próprias capelas privativas nos templos e os oficiais mecânicos de maiores posses determinavam o sepultamento acima das grades. As áreas da nave e do adro parecem ter sido solicitadas pelos indivíduos de menores posses. Outros testadores parecem ter seguido critérios devocionais e místicos: o seu sepultamento perto do altar de um santo servia como forma de honrar a sua devoção e de se acolher sob a sua intercessão salvífica.

O levantamento destas hipóteses explicativas é motivado pelo facto de, na verdade, a maioria dos testadores analisados, cerca de $57 \%$, não ter enunciado qualquer motivo concreto que justificasse a sua opção sepulcral, mesmo ao nível dos templos pelos quais optava. Os fundamentos das escolhas seriam suficientemente claros para estes indivíduos, bem como para os seus herdeiros e testamenteiros, não justificando explicações escritas. De qualquer modo, $43 \%$ dos testadores da nossa amostra deixaram mencionadas as razões que estavam por detrás dessa opção. Esta percentagem importante merece por isso uma análise mais detalhada. As suas escolhas, efetivamente, parecem resumir-se a três motivos fundamentais, dois dos quais já foram por nós enunciados como hipóteses explicativas: o facto de a igreja escolhida ser a da paróquia a que o testador pertencia, ou o de ser a igreja da irmandade da qual o testador fazia parte, 57 correspondendo, em ambos os casos, a uma percentagem de 14\%. Deste modo, constatámos a presença de um critério de pertença a uma comunidade em vida, que os indivíduos queriam manter após a morte. Essa comunidade podia ser de âmbito paroquial ou confraternal. Eram laços sociais e religiosos criados que se desejavam prolongar após o óbito, para que os membros da paróquia e os confrades das irmandades a que o defunto pertencera, ao estarem perto dos restos mortais deste, os mantivessem na lembrança e pedissem a Deus pela sua salvação.

\footnotetext{
${ }^{57}$ Sobre a escolha de sepultura nas igrejas da sua paróquia ou, em alternativa, por se tratar de locais controlados pela sua confraria consulte-se Rivas Álvarez (1986, p. 150-151, 156-157).
} 
Na verdade, a comunidade mais próxima do indivíduo desempenhava um papel fundamental na questão da sua salvação, quando a hora da morte se aproximava. Ninguém podia esperar alcançar a salvação por si mesmo, sem o auxílio dos outros. A presença da família, de vizinhos, do sacerdote e de membros das confrarias, se o agonizante a elas pertencesse, eram fundamentais, com as suas orações implorando a Deus pela salvação da alma daquele que partia. Estes factos eram a tradução da inexistência de uma barreira clara entre o domínio público e privado na vida do homem ocidental na Idade Moderna. 58

Um terceiro fundamento, menos importante, que os testamentos deixaram transparecer, era o da escolha tumular ser motivada por critérios familiares, fator avançado por $8 \%$ de todos os 250 testadores analisados. 59 Na verdade, houve quem quisesse ser enterrado numa determinada igreja, por ser no seu interior que estavam sepultados os seus parentes. Por vezes, essa sepultura era comprada para servir como túmulo familiar. Valorizava-se, deste modo, o núcleo familiar mais próximo, manifestando os testadores o desejo de que este se mantivesse depois da morte. Era uma dupla ambição: ansiavam pela reunião da sua alma com as dos seus entes queridos, no além, enquanto os seus corpos permaneceriam igualmente juntos neste mundo, até à ressurreição final. Por outro lado, a posse de uma sepultura de cariz familiar, dentro das igrejas, era uma forma de perpetuar a memória e manter a distinção social de uma família para os tempos futuros.

\section{Conclusão}

No século XVIII, para os bracarenses que elaboravam o seu testamento, era uma questão fulcral a escolha do local de repouso dos seus restos mortais, esperando o dia do juízo final. Era notória a preocupação primeira pela busca do solo sagrado de um espaço religioso, como forma de garantir a salvação no além, o

\footnotetext{
${ }^{58}$ Leia-se a este respeito Lebrun (2009, p. 92-93) e Castan (2009, p. 402-403).

${ }^{59} \mathrm{Em}$ relação à importância do fator familiar na escolha da sepultura na Época Moderna confira-se Alemán Illán (1988, p. 112).
} 
que se traduzia na determinação de enterro nas igrejas. Este anseio pelo solo sagrado era patente. Não encontramos nas fontes documentais o levantamento de quaisquer preocupações higienistas, por parte dos testadores, relativamente às implicações do sepultamento dos seus restos mortais nos templos. Recorde-se que no mundo ocidental setecentista, o pensamento iluminista emergente criticava este tipo de sepultamentos como contrários à saúde pública, devendo por isso ser interditos. ${ }^{60}$

Por outro lado, os critérios comunitário-paroquiais, familiares e confraternais parecem ter sido fatores com relevância, relativamente à escolha do local de repouso dos restos mortais. A localização do corpo do defunto pretendia, deste modo, reproduzir e manter próximos de si os principais laços de sociabilidade por ele desfrutados em vida, no seio da célula familiar, da comunidade sócio-religiosa e da estrutura confraternal em que se inserira. ${ }^{61}$ Deve, todavia, recordar-se que a maioria dos testadores analisados não se debruçou sobre este assunto. É possível, no entanto, que, também para esses, os motivos aqui enunciados estivessem presentes, embora não sentissem necessidade de os referirem.

Um aspeto importante a relembrar é a importância dos templos construídos por confrarias locais que parecem ter tomado a primazia às igrejas paroquiais citadinas enquanto locais de destino último dos corpos dos bracarenses. É certo que, deste modo, competiam com aqueles templos relativamente aos rendimentos das sepulturas interiores. Não podemos todavia negar que, simultaneamente, estas instituições, com as suas igrejas particulares, desempenhavam um papel utilitário na gestão da morte: elas contribuíam para o "descongestionamento" dos espaços tumulários paroquiais, propiciando maior eficiência nesta questão.

\footnotetext{
60 Relativamente a estas críticas confira- se Catroga (1999, p. 49).

${ }^{61}$ Ariés (1989, p.119-120) resumiu as razões da escolha da sepultura em duas fundamentais: a piedade religiosa, através da escolha das igrejas paroquiais, conventuais, confraternais ou de um santo de devoção; e a piedade familiar, mediante a escolha de uma sepultura familiar ou próxima dos restos mortais dos antepassados.
} 
A análise dos dados em questão demonstra certas continuidades relativamente a esta temática. Há, no entanto uma especificidade bracarense, relacionada com os sepultamentos, que queremos igualmente relevar nesta conclusão. Efetivamente constatámos, a partir de meados da centúria, que um número crescente de testadores passou a designar as igrejas da cidade, como os locais de depósito dos seus restos mortais, durante o período de velório. Nas últimas décadas do século eram, aliás, em número superior aos que assim não o faziam. Portanto o período entre a ocorrência da morte e o sepultamento do defunto transitou progressivamente do espaço doméstico para o espaço eclesial, parecendo traduzir uma certa evolução de mentalidade, a qual recusava a permanência dos corpos nas habitações e pretendia que o velório decorresse próximo ao local de sepultura.

\section{REFERÊNCIAS}

ALEMÁN ILLÁN, A. Actitudes colectivas ante la muerte en Múrcia durante el siglo XVIII. Cadernos de História Moderna, Madrid, nº 9, p. 95-120, 1988.

ARAÚJO, A. C. A morte em Lisboa. Atitudes e representações 1750-1830. Lisboa: Ed. Notícias, 1997.

ARAÚJO, M. M. L. As Misericórdias e a salvação da alma: as opções dos ricos e os serviços dos pobres em busca do Paraíso (séculos XVI-XVIII). In FARIA, A. L; BRAGA, I. D.

Problematizar a História. Estudos de História Moderna em homenagem a Maria do Rosário Themudo Barata. Lisboa: Caleidoscópio, 2007, p. 383-402.

ARIEIRO, J. B. C. Santa Casa da Misericórdia de Arcos de Valdevez. Arcos de Valdevez: Jotasá, 2001.

ARIÉS, P.Essais sur l'histoire de la mort en l'occident.Du moyen-age a nos jours.Paris: EditionsduSeuil, 1975.

ARIÉS, P.Sobre a história da morte no Ocidente. Lisboa:Editorial Teorema, 1989. BINSKI, P.Medieval death: ritual andrepresentation.New York: Cornell University Press, 1996. 
CAMPOS, A. A. A ideia do Barroco e os desígnios de uma nova mentalidade: a Misericórdia através dos sepultamentos pelo amor de Deus na paróquia do Pilar de Vila Rica (1712-1750). In ÁVILA, A.O território do Barroco no século XXI. Ouro Preto: Roma Editora, 2000, p. 45-62.

CARVALHO, E. M. D. da C. A fortuna ao serviço da salvação da alma da família e da memória, através dos testamentos dos arcebispos e dignatários de Braga na Idade Média

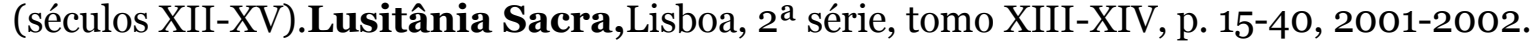

CASTAN, N. O público e o particular. In ARIÈS, P.; DUBY, G. História da vida privada, vol. 3: da Renascença ao século das Luzes. São Paulo: Companhia das Letras, 2009, p. 402-438.

CASTRO, M. de F.A irmandade e Santa Casa da Misericórdia de Braga. Braga: Santa Casa da Misericórdia de Braga e autora, 2001.

CASTRO, M. de F.A Misericórdia de Braga. Assistência material e espiritual, vol. III. Braga: Santa Casa da Misericórdia e Autora, 2006.

CATROGA, F. O Céu e a Memória. Cemitério romântico e culto cívico dos mortos, 1756-1911. Coimbra: Livraria Minerva Editora, 1999.

Constituições Synodais do Arcebispado de Braga ordenadas no anno de 1639 pelo illustríssimo Senhor Arcebispo D. Sebastião de Matos Noronha e mandadas imprimir a primeira vez pelo illustríssimo Senhor D. João de Sousa. Lisboa: na oficina de Miguel Fernandes, 1697.

CHAUNU, P.La mort à Paris, XVI, XVII, XVIII siécles. Paris: Fayard, 1978.

FARIA, I. M. de. A Igreja e o povo na vida e na morte séculos XVIII a XX (estudo com base em visitas pastorais e testamentos).NW, Noroeste. Revista de História, Congresso Internacional de História Territórios, Culturas e Poderes, Actas, Braga, vol. I, p. 785-802, 2006.

FAVRE, R.La mort dans la literature et la pensée françaises au siécle des lumiéres.Lyon: Presses Universitaires de Lyon, 1978.

GARCÍA FERNÁNDEZ, M.Herencia y património familiar en la castilla del antíguo régimen (1650-1834). Efectos socioeconómicos de la muerte y la partición de bienes. Valladolid: Secretariado de Publicaciones Universidad de Valladolid, 1994.

GARCIA FERNÁNDEZ, M.Los castellanos y la muerte, religiosidade y comportamentos colectivos en el Antíguo Régimen. Valladolid: Junta de Castilla y Léon, 1996.

GARCÍA GARCÍA, F. El ritual de la muerte en Zalamea La Real en la segunda mitad del

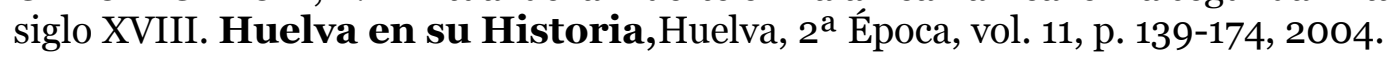


GREGÓRIO, R. D. Configurações do patrocínio religioso de um ilustre açoriano do século XVI o $1^{\circ}$ Provedor das Armadas, Pero Anes do Canto. Arquipélago - História, Ponta Delgada, $2^{\text {a }}$ Série, III, p. 29-44, 1999.

GOMES, P. A. de C. S. Oficiais e confrades em Braga no tempo de Pombal. (Contributos para o estudo do movimento e organização confraternal bracarense no século XVIII). Braga: Universidade do Minho, 2002.

LEBRUN, F. As Reformas: devoções comunitárias e piedade pessoal. In ARIÈS, P.; DUBY, G. História da vida privada, vol. 3: da Renascença ao século das Luzes. São Paulo: Companhia das Letras, 2009, p. 76-112.

LORCIN, M.-T. Choisir um lieu de sepulture. In ALEXANDER-BIDON, D.; TREFFORT, C.A réveiller les morts. La mort au quotidien dans l'occident medieval. Lyon: Presses Universitaires de Lyon, 1993, p. 245-253.

MARTÍNEZ GIL, F.Muerte y sociedad en la España de los Austrias.Madrid: Siglo XXI de España Editores, 1993.

MARTÍN GARCÍA, A. Religión y sociedad en Ferrolterra durante el Antiguo Regímen. La V. O. T. seglar franciscana.Estudios Mindonienses, Salamanca, $n^{0}$ 20, p. 395-602, 2004.

MORAES, Juliana de Mello. Viver em Penitência: os irmãos terceiros franciscanos e as suas associações, Braga e São Paulo (1672-1822). Braga: Universidade do Minho, 2009

MONTÉROS SÁNCHEZ, F. E. La religiosidad popular gaditana a través de las disposiciones testamentarias del siglo XVI. Trocadero, Cádiz, (17), p. 147-162, 2005.

MÓRAN, M.; ANDRÉS-GALLEGO, J.O pregador. In VILLARI, R.O Homem Barroco. Lisboa: Editorial Presença, 1995, p. 117-139.

NEVES, A.A Misericórdia de Aveiro nos séculos XVI e XVII. Aveiro: Santa Casa da Misericórdia de Aveiro, 1998.

OLIVEIRA, E. P., André Soares e o Rococó do Minho. Vol. I. Porto: Universidade do Porto, 2011.

PINA, I. C. Ritos e imaginário da morte em testamentos dos séculos XIV e XV. In MATTOSO, J. O reino dos mortos na Idade Média peninsular. Lisboa: Edições João Sá da Costa, 1996, p. 125-164.

RAIMUNDO, R. V.Morte vivida e economia da salvação em Torres Novas (16701790). Torres Novas: Município de Torres Novas, 2007. 
REDER GADOW, M.Morir en Malaga. Testamentos malagueños del siglo XVIII. Málaga: Universidad de Málaga, 1986.

REIS, J. J.A morte é uma festa: ritos fúnebres e revolta popular no Brasil do século XIX. $4^{\text {a }}$ edição. São Paulo: Companhia das Letras, 2004.

RIVAS ÁLVAREZ, J. A.Miedo y piedad: testamentos sevillanos del siglo XVIII. Sevilha: Diputación Provincial de Sevilla, 1986.

ROQUE, J. L.Atitudes perante a morte na região de Coimbra de meados do século XVIII a meados do século XIX, notas para uma investigação. Coimbra: Faculdade de Letras da Universidade de Coimbra, 1982.

RUBIO SEMPER, A.Piedad, honras fúnebres y legados piadosos en Aragón (Calatayud) en la baja Edad Media. In SERRANO MARTÍN, E.Muerte, Religiosidad y Cultura Popular. Siglos XIII-XVIII.Zaragoza, Instituto Fernando el Católico, 1994, p. 241-277.

SÁ, I. dos G. Misericórdias. In AZEVEDO, C. M., Dicionário de História Religiosa de Portugal. Lisboa: Círculo de Leitores, 2000, p. 200-203.

SANTIAGO, S. Iconografia del claustro barroco en Portugal, Espana, IberoAmerica. InI Congresso Internacional do Barroco, Actas, II volume. Porto, Reitoria da Universidade do Porto; Governo Civil do Porto, 1991, p. 403-419.

SILVA, R. M. A. Casar com Deus: vivências religiosas e espirituais femininas na Braga Moderna. Braga: Universidade do Minho, 2011.

SOARES, F. N. A Missionação da arquidiocese de Braga pelas visitas pastorais nos séculos XVI e XVII. In Actas do Congresso Internacional de História Missionação Portuguesa e Encontro de Culturas, Vol. I.Braga: Universidade Católica Portuguesa; Comissão Nacional para as Comemorações dos Descobrimentos Portugueses; Fundação Evangelização e Culturas, 1993, p. 313-344.

SOARES, M. I. E a sombra se fez verbo: quotidiano feminino setecentista por Braga. Braga: Associação Comercial de Braga, 2009

VELOSO, M. T. N.A morte nos testamentos dos clérigos bracarenses do século XIII.Coimbra: Faculdade de Letras da Universidade de Coimbra, 1988. 